\title{
Curricular renewal at the southern tip of Africa: The '2016' veterinary curriculum at the University of Pretoria
}

Peter C Irons

College of Veterinary Medicine, Murdoch University, 90 South Street, Murdoch WA 6149, Australia

PhD DipACT

Veterinary Program Director

P.Irons@murdoch.edu.au

orcid.org/0000-0002-7374-9720

Dietmar E Holm

BVSC MSc PhD

Deputy Dean: Teaching and Learning, Faculty of Veterinary Science, University of Pretoria

\section{Henry Annandale}

BVSc (Hons) MMedVet(Gyn) MBA Dip ACT

Department of Production Animal Studies and Director Clinical Services, Faculty of Veterinary Science, University of Pretoria

\begin{abstract}
Four years after the institution of a new curriculum at the University of Pretoria's Faculty of Veterinary Science, a second major curricular renewal was initiated as a result of several pressing drivers, many of which were unique to the national and institutional context. During the project, South African higher education was disrupted by student protests prompted by financial pressures on students, the overt colonial structure of higher education, and the need to accelerate transformation of the sector. A structured curricular renewal process was followed, including the laying down of the principles, the structuring the macro-curriculum as a story, the design of a meso-and microcurriculum, and the mapping of the curriculum to Day One outcomes. The resulting program is a 6year bachelor's degree with a blend of discipline and species modules, with the first cohort graduating in 2016. There is a strong focus on skills embodied in a 62-week experiential component, managed using a unique custom-designed online platform for booking placements, documenting exposure, assessing competency, and providing feedback to students. The experiential training includes a large elective component. Several causes of loss of impetus during the process are discussed and proposals are made for avoiding these. The value of accreditation as a driver and a source of inputs is evident. The process has succeeded in producing a significantly reshaped curriculum that has been well received by external stakeholders.
\end{abstract}

\section{Key words}

Veterinary curriculum renewal, transformation, veterinary medical education, curriculum, climate, 2016 BVSc, University of Pretoria

\section{Introduction}

This article documents in broad strokes the creation of a new veterinary curriculum at the Faculty of Veterinary Science, University of Pretoria, highlighting unique drivers, novel approaches and lessons learned in the process.

Saying that much has changed since the last publication on the veterinary curriculum in South Africa is a gross understatement. While those authors described the impact of powerful forces such as globalization, climate change, emergence and re-emergence of diseases, and several locally-relevant socio-economic factors on veterinary education, ${ }^{1}$ they could not have predicted the upheaval in the national university sector which is currently underway. Symptomatic of this is a new vocabulary, with terms such as 'transformation' and 'decolonization' being used routinely in discourse surrounding higher education whereas they did not feature in the 2009 paper (although it did outline the Eurocentric history of veterinary training on the continent).

Several socio-economic realities have become increasingly evident in the interval since 2009, culminating in a sustained barrage of protest actions against various aspects of the tertiary (university 
and post-school vocational training) educational landscape since 2015. The increasing financial burden placed on students due to above-inflation rises in tuition fees and inadequate support schemes for poorer students was one of the primary issues, leading to the labeling of the movement as the 'FeesMustFall' campaign. ${ }^{2}$ The second major issue was the persistence of powerful symbols of the colonial history of tertiary institutions and the lack of adoption of more diverse epistemologies, epitomized by the 'RhodesMustFall' movement that rejuvenated the theme of decolonization of higher education. ${ }^{3}$ This is part of a pervasive discontent with the pace of transformation in the sector, fuelled by the obvious aspects of a lack of gender and racial representation and the traditional, strongly hierarchical structures of most educational institutions. Underlying these issues is the pressure placed on higher education by the inadequate state of readiness for tertiary education of students graduating from secondary school, despite large resource allocation and extensive reform of basic education in the post-apartheid era. ${ }^{4}$ The fact that none of this has been specifically focused on veterinary education does not exempt us from scrutiny nor from the implications and direct consequences of these actions, which highlight the urgency and importance of curriculum renewal.

As an example of direct effects of the above events on the institution, additional strategies were instituted to influence the composition of the student body such that it is more representative of the national demographic, requiring the allocation of greater resources to student recruitment and support.

There were also significant events of more specific bearing to veterinary education in South Africa. Compulsory community service for veterinary graduates was introduced in 2016 by amendment of national legislation; requiring graduates to spend a year in strategic placements to strengthen veterinary services in those areas. This places an increased onus on the institution to produce graduates able to perform in that environment. In response to requests from government the institution increased its intake of veterinary students by $35 \%$ utilizing state funding for infrastructural developments, again during the lifetime of the curricular renewal project described here. Diversity of the student body has also increased rapidly, placing new demands on educational and student support structures and practices. All of these have elicited renewed attention on the veterinary program both internally and externally. This scrutiny is all the more intense given the institution's position as the sole provider of veterinarians in a large and diverse nation.

This manuscript will focus on curricular change primarily, but make reference to pertinent contextual aspects which have been propelled onto the national higher education agenda as the project has progressed. It is written with the full awareness that much has yet to be done in this regard.

The curricular renewal project which is the focus of this paper began in July 2007 in response to issues raised by the accreditation body and concerns from stakeholders regarding the implementation of a two-degree structure, the so-called 3+4, in 2003. The 3+4 consisted of a 3-year bachelor of veterinary biology (BSc (VetBiol)), which was a prerequisite for entry into the 4-year bachelor of veterinary science (BVSC). Students were selected for the BVSc during the third year of the BSc (VetBiol).

The first cohort of students entered the new programme in January of 2011 and will graduate at the end of 2016, it being a six-year programme culminating in a bachelor degree in veterinary science. For the purposes of this discussion the programme will be referred to as the '2016 BVSc'.

The major curricular changes are summarized as the reduction from two to one degree; the reduction in programme duration by a year; the reduction in didactic teaching component by 3 semesters; and the increase in the experiential component by including a sizable elective component informed by career choice. Other innovations and the approach to instituting these changes are detailed in the text. 


\section{Birth and development of the 2016 BVSc}

\section{From drivers to objectives}

Curriculum renewal is not embarked upon lightly so it is clear that there were strong drivers for the insitution to initiate this process so soon after the implementation of a new programme. The most compelling were duration and cost of the $3+4$ programme. Higher education is heavily subsidised in South Africa, but there is still a substantial cost to the student. While the $3+4$ structure initially realised increased government income for the insitution, the subsidy formula changed shortly after implementation making it less financially favourable.

An additional driver was the fact that admission to the second degree was not assured and that graduates of the BSc (VetBiol) programme who did not gain admission to the BVSc did not have a clear career path. The competitive culture which was created amongst students prior to selection into the second degree was also felt to be damaging to the stated outcome of good professional collaboration.

Curricular matters including the lack of clear constuctive alignment between the first and the second degree programmes of the $3+4$ program were also considered.

The various drivers were crystallised into a set of key objectives for the project which were developed at the outset. Some addressed student access which will not be discussed here. Selected principles pertinent to curricular renewal are paraphrased as follows:

- To meet the needs of the country and the subregion and be internationally acceptable;

- To produce a veterinarian with a sufficiently comprehensive set of core skills to enable them to adapt to the demands of general rural and urban, state veterinary and public health practice;

- For graduates to have a higher degree of confidence in a specific career choice within the profession through the completion of elective components utilising a combined local and distributive model;

- To shorten the programme from seven years to a total of five to six years and accommodate direct entry from secondary school;

- To embed a rich mix of teaching and learning modalities and technologies;

- To ensure that assessment is a key aspect of curriculum development;

- To address 'information overload';

- To provide exposure to the principles of scientific investigation and reporting;

- To provide opportunities for the development of life skills including communication and business skills; and

- $\quad$ For the programme to progress from a more discipline-based approach in the core component and, where relevant, more species-based in the elective and experiential components.

Ideally one would perform a comprehensive evaluation of the existing curriculum at the outset to inform any curricular renewal process. It was not possible to perform a comprehensive evaluation of the preceding $3+4$ programme in this instance because the first cohorts were at an early stage of the $3+4$ programme when this process was initiated. However, what data was available at that time was indeed interrogated. This consisted mainly of the internal assessment of the programme done in preparation for, and the external report emanating from the South African Veterinary Council (SAVC) and Royal College of Veterinary Surgeons (RCVS) accreditation visitation of 2006. Findings of the next visitation, being a combined audit performed by the SAVC, RCVS and Australasian Veterinary Boards Council (AVBC) in 2013, were also considered in the evolution of the experiential component of the programme.

Similarly, given the evident nature of the needs for the new product which were communicated by stakeholders and the detailed feedback from the accrediting bodies, a systematic needs assessment was not embarked upon. Strategic internal and external stakeholder consultation was nevertheless 
included in the process. Research in international practice, envisioning reports and relevant opinion pieces was also shared amongst the working group.

\section{The structures and decision-making}

While the process was driven in the initiation phases by the Dean, it was managed for the most part through the faculty's curriculum committee by means of the establishment of an independent working group with academic staff representation from all five academic departments. This group, with membership separate to that of the curriculum committee, was tasked to finalize the objectives and outcomes of the programme, going through all levels of curriculum design (designing macro-, meso- and micro-curriculae as described by van den Akker at al. ${ }^{5}$ ), soliciting the inputs of relevant staff and other experts where necessary, and making recommendations on these matters to the faculty through the curriculum committee, chaired by the Deputy Dean: Teaching and Learning. A fulltime senior staff member was appointed and given the necessary ring-fenced resources to lead this process. Some high level philosophical drivers of the project including the relative weighting of modules in terms of credits and the allocation of contact time to each, as well as the development of the organizational components of years or modules and the coordination mechanisms between modules were the domain of the curriculum committee chaired by the Deputy Dean.

Decisions supported by the curriculum committee were subject to further approval through the relevant faculty and institutional governance structures consisting of the Faculty Board and University Senate and were subject to the relevant decision-making processes, including voting rights for all faculty.

\section{The outcomes statement}

Following the establishment of the key principles detailed above, the working group focused on the programme outcomes. The outcome of these deliberations was to adapt, with minor amendments, the outcomes statement of the Royal College of Veterinary Surgeons. ${ }^{6}$ The document lists 13 general professional skills and attributes, 10 areas of underpinning knowledge and understanding, and 23 practical competencies which a student is expected to achieve by the completion of the core curriculum. Collectively they form the 'Day One Competencies' for the programme. The document further defines the concept of 'common domestic species', which is used under several items. It is also evident from commentary insertions interspersed through the document that there was a need to futher clarify a number of aspects beyond a simple statement of the requirement. Indeed, the lack of a more detailed and specific list of what exactly to include for which species to guide the process from the outset is an aspect to consider for future similar processes.

A generic set of outcomes for the elective component, focused on the general professional skills and attributes, were developed at a later stage of the process.

The further development of the practical competencies component is dealt with in the section on the experiential training phase.

\section{Macro-, meso- and microcurriculum design}

Once the above fundamentals were in place, the hard work of designing a macrocurriculum including the year and module structure, year-by-year meso- \& micro-curriculum design, and allocating credits and contact time was embarked upon. Documents were prepared by relevant discipline teachers using pre-agreed templates, followed by detailed review by the working group. These documents detailed the content and organization of each module, as well as the alignments to programme outcomes. Except for the macro-curriculum, this was done in a year-by-year manner from the first year onwards, with the relevant documents passing through institutional approvals on an annual basis as they were completed. With the exception of two small modules the first year was largely excluded from this process as it was composed of pre-existing modules offered in other faculties to students from a range of other science programmes. 
Early in this process a week-long workshop was held for work group and committee members with international veterinary educational specialists. Various in-house training sessions in curriculum design were also conducted and best-practice materials were provided by the institution's educational support service.

A crude curriculum mapping tool was prepared during the work group's deliberations. This consisted of a spreadsheet with the programme outcomes and relevant sub-categories in rows and the modules in columns, with scores on a three-point scale in each cell indicating cross-matching to the degree of address of the outcomes for each individual module. This was used to check the coverage periodically and was very useful in post-production review.

\section{Review and refinement}

Review was conducted as an ongoing process throughout as well as the culmination of the renewal project; while assessment of final outcomes will only be possible once the first graduates have been produced. In terms of in-process review, modules were put out to internal and external review as the development of each one was completed. Internal review was overseen by the curriculum committee, while external reviewers were nominated by the relevant discipline specialist. This was done at an intermediate stage between development and final approval to allow for refinements to be made prior to execution. Students also had the opportunity to contribute at various stages by means of feedback to the unit coordinator and through representation on the curriculum committee.

Once the entire curriculum had passed through the design phase, post-production review was performed in the form of a focused workshop with committee members and external stakehoders; the results of which were fed back to the curriculum committee. The focus was on the objectives of the project and whether these had been met in the new curriculum. Inputs for this process were entirely internally-generated. The mapping tool described above proved to be a very effective means of obtaining an overview of coverage of the programme outcomes in this process.

Unavoidably with the phasing-in as outlined above, there is overlap between completion of the project and enhancement of those portions of the programme which are already in operation. Besides lessons emanating from execution, new imperatives also arise, in this case including the forces discussed in the introduction and the new institutional strategic direction and academic plan. ${ }^{7}$ Iterative changes which have been made or are in consideration include the restructuring of the original plans for the elective and the research components and restructuring of the first and second years to facilitate entry into the second year. Recent resurgence of language and the political power of language policy in higher education in the national discourse led to intense reconsideration of these issues within the institution, culminating in the revision of the university's language policy and the implementation of a multilingual glossary of terminology relevant to the discipline. Recent changes to other academic programmes have also opened the way to revisions of content in the areas of animal husbandry, nutrition and cross-disciplinary collaboration to strengthen alignment to the programme outcomes. For the most part these changes were necessitated by external drivers, but some were the result of internal feedback to the curriculum committee from staff and students.

During phasing in of the new curriculum, some faculty were required to teach in both the old and new curriculum, in the case of material that moved to an earlier year in the 2016 BVSc curriculum. This was managed by offering the material during different semesters within the academic year.

\section{The product}

The programme is a six-year bachelor's degree with entrance of secondary school-leavers into the first year and of candidates with suitable university training into the first and second years. The programme is crudely divided into $41 / 2$ years of didactic teaching (theory supported by a significant practical training programme) followed by 18 months of experiential training and elective exposure. While some consideration was given to shorter programmes, the inclusion of a significant elective component and the expediency of utilizing the 'shell' of the earlier 6-year version of the degree which 
was still included in the institution's approved programme-qualification catalogue were the deciding factors.

The macro-curriculum was developed in an attempt to tell a story, inspired by the Dragon Slayers' Curriculum of Roger Schank, ${ }^{8}$ and was named the 'story curriculum' during development in order to keep committee members focused on its logical structure. Mandler and Johnson reasoned that folklore stories have developed a specific structure as a result of people's ability to retrieve facts and events when they are ordered in a specific logical way. ${ }^{9}$ The team therefore attempted to construct a curriculum that is built on these principles, in the belief that this will improve learning. The 'story' presented in our curriculum was structured in stages, around a theme for each year of the didactic part of the programme, and ordered in a logical and progressive manner as follows:

Exposition: In the first year the scene is set with the basic underpinning sciences as benchmark courses to ensure understanding of later courses in biology;

Rising action: The themes then develop through the specific veterinary disciplines in the second and third years;

During the fourth year and first semester of the fifth year, the exiting applied clinical species-based modules and population-related modules form the 'climax' of the story;

The conclusion of the story is represented by the experiential component, during which all of the preceding chapters are brought together, concluding with the final single Day One competency examination.

The 'story' is further complemented by the yearly module on 'Veterinary Professional Life', which acts as a golden thread that binds the 'story curriculum' together, with the additional objective of strengthening the development of life skills. In this module, the story starts with an introduction to the profession and its relevance in the economy (first year), then looks at self-discovery, stress management and understanding other role players such as clients (second year), then develops further looking at ethical and welfare considerations within the profession and cultural awareness and communication skills (third and fourth years) and concludes with business skills in the semester preceding the experiential training phase. This 'golden thread' accounts for almost $5 \%$ of the total credits in the didactic component.

Once the broad themes were in place for each year the years were populated with the relevant modules. The need to comply with guidelines on the total credit-bearing of each year informed the allocation of credits to the respective modules in the year, which in turn informed the proportional contact time for each. This process, which was done by the curriculum committee, proved to be essential to achieve the objective of addressing 'information overload'. Detailed scrutiny of the content of each module was carried out by the working group, culminating in recommendations on the inclusion and organization of content. The year themes, modules, relative module contribution and credits are shown in Table 1.

Other significant features of the new program are the inclusion of an explicit focus on the development of research awareness and skills, the organization of all content into 'core' and 'elective' categories and a significant strengthening of the elective component, a marked reduction of content and improved constructive alignment of the structure and function content and the introduction of structured documentation of procedures and skills assessment. The latter is detailed later in the text.

\section{Pedagogy and delivery}

The 2016 BVSc is the first curriculum at this school which explicitly aligned all content to programme outcomes. This has been paralleled by an institutional shift to inquiry-led teaching and learning which was formalized during the life of this project.

Educational innovation has facilitated the shift in pedagogy to a more student-driven, outcomesbased model. Presentation of content has migrated to a hybrid model utilizing a variety of multimedia resources, delivered mainly through an online learning management system with the capability to record student performance. ${ }^{a}$ The use of electronic technology to enable real-time in-class polling of students to facilitate learning was also implemented. 
Table I: Year themes, modules, relative module contribution, and credits for the 2016 BVSc

\begin{tabular}{|c|c|c|c|c|c|}
\hline $\begin{array}{l}\text { Year I: } \\
\text { natural sciences }\end{array}$ & $\begin{array}{l}\text { Year 2: } \\
\text { basic veterinary } \\
\text { disciplines }\end{array}$ & $\begin{array}{l}\text { Year 3: } \\
\text { causes and } \\
\text { effects of disease }\end{array}$ & $\begin{array}{l}\text { Year 4: } \\
\text { veterinary diagnostics } \\
\text { and therapeutics }\end{array}$ & $\begin{array}{l}\text { Year } 5 \\
\text { (first semester): } \\
\text { veterinary } \\
\text { community interaction }\end{array}$ & $\begin{array}{l}\text { Year } 5 \\
\text { (second semester) } \\
\text { and year 6: } \\
\text { experiential phase }\end{array}$ \\
\hline Chemistry*** & $\begin{array}{l}\text { Vet comparative } \\
\text { anatomy*** }\end{array}$ & $\begin{array}{l}\text { General and organ } \\
\text { pathology*** }\end{array}$ & $\begin{array}{l}\text { Small-animal medicine and } \\
\text { surgery*** }\end{array}$ & $\begin{array}{l}\text { Bovine health and } \\
\text { production } * * *\end{array}$ & Vet core practice \\
\hline Biometry** & Vet physiology and histology*** & $\begin{array}{l}\text { Introductory vet } \\
\text { diagnostics } * * *\end{array}$ & Diagnostic imaging $* * *$ & $\begin{array}{l}\text { Small stock health and } \\
\text { production } * * *\end{array}$ & Vet elective practice \\
\hline Mathematics** & Vet ethology and genetics $* * *$ & Vet parasitology*** & Vet reproduction $* * *$ & Vet public health** & \\
\hline Molecular and cell biology** & Animal ecology $* * *$ & Vet pharmacology** & Diagnostic pathology** & Vet epidemiology** & \\
\hline Physics** & Animal science $* * *$ & Vet infectious diseases** & Equine medicine and surgery** & Vet business management $* *$ & \\
\hline Medical terminology** & Animal nutrition* & Vet toxicology** & Vet professional life** & Diagnostic pathology** & \\
\hline Animal diversity* & Vet professional life* & Vet professional life** & Anesthesiology* & One Health* & \\
\hline Introductory genetics* & Vet immunology* & General surgery* & Clinical pathology* & & \\
\hline $\begin{array}{l}\text { Academic information } \\
\text { management* }\end{array}$ & Vet microbiology* & & Porcine health and production* & & \\
\hline Language and study skills* & & & Poultry health and production* & & \\
\hline \multicolumn{6}{|l|}{ Vet professional life* } \\
\hline \multicolumn{6}{|l|}{ Academic orientation* } \\
\hline I40 credits $^{\dagger}$ & I55 credits & 135 credits & I49.5 credits & 100 credits & 280 credits \\
\hline
\end{tabular}

$*, * *, * * *=$ small, medium, or large component as measured by $\%$ of credits of entire didactic component of the program

$\dagger$ A credit is deemed to represent 10 notional hours of student endeavor. 
Focused student support has been provided to facilitate these changes and support students with diverse learning needs and approaches, with the strategic appointment of student advisors, tutors and teaching assistants.

While didactic teaching has followed a traditional parallel-presentation structure within semesters, a block system of presentation entailing the presentation of large units of content or entire modules during a dedicated block of time without any overlap with other content delivery is currently being piloted in one year of the programme.

Assessment practices have also been modernized, including the first adoption of structured procedural skills assessment methods (OSCE's and DOPS). This was facilitated by the establishment of a large and well-resourced skills laboratory and the expansion of the experiential phase of the programme.

\section{The experiential training phase}

One of the most far-reaching design features of the '2016' BVSc programme is the expansion of the experiential phase to three semesters. This was a response to several factors. A recurrent theme in student feedback of excessive amounts of theoretical training in the $3+4$ programme was a strong consideration. The second was the expansion of the programme outcomes to include a significant number of non-technical attributes and competencies best inculcated by means of experiential training. The third was to enable maximum flexibility in the inclusion of an expanded elective component by means of allowing scheduling over a longer period. Last but not least, there was a need to reduce formal contact time in the programme as a whole.

The final three semesters are composed of only two modules - veterinary core practice (VCP) and veterinary elective practice (VEP), which entail 42 and 20 weeks equating to 160 and 120 credits respectively. Veterinary core practice is aimed at attainment of the day one competencies and achieves this by integration and application of theoretical knowledge gained in the preceding modules of the programme while also providing opportunities for development and refining of practical skills.

Extending the experiential phase created overlap between cohorts of students, adding another layer of complexity to the planning task. A system that allowed some control over the numbers of students in clinical rotations while ensuring adequate exposure was therefore required.

\section{Developing the platform}

Experiential training is a very complex and costly part of veterinary education, due to the range of exposure which is desirable as well as the resources required to provide the ideal environment. Planning and managing this phase carefully is therefore essential to avoid wasteful use of resources. It is also an extremely onerous task given the multitude of parameters to be factored in.

As a result of these considerations it was decided to develop a system to achieve the following objectives:

- Allow students to follow an individual programme while conforming to a set of predetermined minimum criteria;

- Allow each student to log their exposure against a list of skills and procedures;

- Allow the capturing of the results of skills assessments during experiential training;

- Provide reports for management purposes;

- Enable online access;

- Be amenable to mobile access through the development of an application.

The development team elected to adopt an engineering approach, which led to the creation of an online application branded as 'Vetbox'. This tool assists in providing quality assurance of clinical 
training by allowing logging of procedures, assessment of skills and electronic signing by supervisors, as well as managing the scheduling of rotations and of assessments and providing a channel for communication between teacher and student.

Flexibility for students to fashion their own individual clinical rotation programme was achieved by applying the theory of constraints to the design of the clinical rotations booking module of Vetbox. Briefly, by considering physical space, ambulatory service space and clinicians as resources which could potentially serve as bottlenecks for the "flow" of students through clinical rotations, the most constrained resource could be identified.

Unsurprisingly, the most constrained resource was found to be clinicians, since accreditation bodies require a $1: 6$ or $1: 7$ clinician to student ratio in the experiential phase. Identifying this allowed determination of the optimum number of students per rotation and therefore the parameters of the booking system.

\section{The core rotations}

Table 2 lists the rotations, minimum time that students are required to spend on each in the core, and which are offered in a distributive fashion. Strategic shifts in emphasis from the previous programme included increasing proportional exposure to state veterinary practice, veterinary public health and production animal rotations to strengthen core skills exposure in these areas.

\section{Table 2: Core clinical rotations and durations}

\begin{tabular}{|l|l|}
\hline Clinical rotation & Duration \\
\hline Anaesthesiology & 2 weeks \\
\hline Critical and emergency care in Small Animals & 3 weeks \\
\hline First opinion practice and Spay/neuter & 3 weeks \\
\hline Diagnostic imaging & 1 week \\
\hline Small Animal Internal Medicine & 2 weeks \\
\hline Small Animal Surgery & 2 weeks \\
\hline Pathology & 3 weeks \\
\hline Equine Field Service and Emergency & 1 week \\
\hline Equine Medicine & 2 weeks \\
\hline Equine Surgery & 2 weeks \\
\hline Production Animal Clinic & 3 weeks \\
\hline Production Animal Ambulatory* & 3 weeks \\
\hline Reproduction & 3 weeks \\
\hline Veterinary Public Health & 3 weeks \\
\hline Dentistry and Ophthalmology & 1 week \\
\hline State veterinary core practice* & 2 weeks \\
\hline Community Engagement Clinics* & 2 weeks \\
\hline Private Practice* & 4 weeks \\
\hline TOTAL & 42 weeks \\
\hline
\end{tabular}

* Rotations utilizing distributive training

Each of the rotations in Table 1 was divided up into single weeks, and for each week the service could set a maximum and minimum number of students which could be accommodated. This enabled students to book within these parameters using a panoramic view which indicated which weeks were close to or at capacity.

\section{The elective}

The purpose of the elective module is to give students additional exposure in a practice area of their choice, and to strengthen the degree of address of some of the general professional attributes. Six different elective themes were developed for the veterinary elective practice module and ranges of 
proportions of the class of students to be allocated to each theme were determined after an extensive consultation process (Table 3 ). The main factors considered during this process were expectations of students, estimated future market demand, capacity constraints from supervision and caseload point of view and perceived government needs and expectations.

The question of the sequence of core and elective exposure elicited a variety of very strong views. While it is standard within scientific disciplines to follow a hierarchical approach of progressing from theoretical to more applied material (equating to core followed by elective), experience with a teaching project within at the Faculty had shown the power of the converse approach of workplace learning followed by exposure to theoretical underpinning and reflection. As consensus could not be reached between the different elective themes a system that allowed sufficient flexibility to cater for a variety of approaches was adopted.

The broad guidelines for utilization of the twenty weeks were agreed on by a task team and approved by the curriculum committee, within which each theme developed their individual programme. This included prerequisite and elective-elective weeks. Following this process, topics were developed to populate each of the elective themes, including topics of relevance to more than one theme where possible. Each topic within the themes consists of a didactic and experiential component, with strong elements of self-directed learning and peer instruction in the educational approach.

Table 3: Elective themes, content and proportions of class

\begin{tabular}{|c|c|c|}
\hline Elective theme & Topics included & $\begin{array}{l}\text { Proportion of } \\
\text { class }\end{array}$ \\
\hline Small Animal and Exotics & $\begin{array}{l}\text { Small animal medicine, surgery, reproduction, } \\
\text { diagnostic imaging, clinical pathology, ophthalmology, } \\
\text { dentistry, anaesthesiology and exotic pets }\end{array}$ & $42-50 \%$ \\
\hline Rural and Wildlife & $\begin{array}{l}\text { Cattle herd health, small stock flock health, } \\
\text { epidemiology, economics, wildlife management and } \\
\text { conservation, drug regulations and pathology. }\end{array}$ & $16-19 \%$ \\
\hline $\begin{array}{l}\text { Veterinary Public Health } \\
\text { and State Veterinary }\end{array}$ & $\begin{array}{l}\text { Veterinary public health, controlled diseases, primary } \\
\text { animal health care, epidemiology, import/export } \\
\text { regulations, laboratory tests, pathology and } \\
\text { certification }\end{array}$ & $11-13 \%$ \\
\hline Equine & $\begin{array}{l}\text { The equine industry, medicine, surgery, reproduction, } \\
\text { nutrition, dentistry, diagnostic imaging, } \\
\text { anaesthesiology and certification }\end{array}$ & $8-9 \%$ \\
\hline Intensive Animal Production & $\begin{array}{l}\text { Poultry health, porcine health, dairy and udder health, } \\
\text { feedlot health, aquaculture, ostriches, epidemiology, } \\
\text { economics, certification, drug regulations, controlled } \\
\text { diseases and pathology. }\end{array}$ & $8-9 \%$ \\
\hline Research & $\begin{array}{l}\text { Grant writing, research methodology, epidemiology, } \\
\text { statistical analyses, economics, laboratory tests, } \\
\text { laboratory animal science, pathology and scientific } \\
\text { writing and publication }\end{array}$ & $0-3 \%$ \\
\hline
\end{tabular}

Students are allocated elective themes by following an iterative process of allocation according to their ranked preferences, with an appeal following the final allocations if necessary.

Assessment in the veterinary elective practice module is made on the generic outcomes common to all themes and takes the form of a rubric assessing professional conduct, communication, retrieval and organization of information, practical application of knowledge, holistic approach to problems, technical skills and professional confidence. The assessment is formative in nature and no grade is assigned. 


\section{Maintain > Skills}

\section{Assessments -}

Maintain -

Statistics -

Progress

Notifications -49

Profile

Logout

Vetbox @ 2016. All rights

reserved.

X suggestions@vetbox.co.za

(2016-06-05.1)

Skill

Administer a subcutaneous injection (medication or fluids)

Administer an intramuscular injection

Administer an intravenous injection

Application of external fixation (cast) for a distal limb injury

Induce anaesthesia by administering a short-acting injectable anaesthetic

Species

Actions

Ovine, Equine, Caprine, Feline, Porcine, Bovine, Exotic \& Game, Avian, Canine

Ovine, Equine, Caprine, Feline, Porcine, Bovine, Exotic \& Game, Avian, Canine

Caprine, Ovine, Equine, Feline, Bovine, Canine

Feline, Canine

Feline, Canine

Figure 1: The online Vetbox interface showing examples of procedures included in the Day One skills list 


\section{The procedures and skills}

A major departure from previous approaches was the development of a Day One skills list, which takes the programme outcomes statement to the next level by means of detailing specific skills and procedures and the relevant species for each which a graduate is expected to have mastered (i.e. Day One on their first job after graduation). The development process entailed using existing publicallyaccessible lists as a basis and incorporating inputs from internal and external stakeholders, thus producing a list of 176 identified skills, applicable to the major domestic, exotic and game species. This is demonstrated in Figure 1, showing the online interface populated with this data. A search function was included to facilitate the quick location of a skill, given the necessity to ease the process for busy users in a clinical service setting.

\section{Skills logging and assessment - The 'Vetbox experiment'}

Skills logging existed in the $3+4$ programme in the form of logbooks signed off by clinicians. In preparation for the core-elective approach, the logbooks were transformed into a web-platform application, which was piloted with the Class of 2015. The application was designed to take the student through three screens, one each for owner, patient and procedure information. Verifiability of the logged skill was achieved by referencing of the patient identification in the hospital management system. The students were given the ability to upload files onto the system and to view their progress.

Student feedback on the Vetbox pilot was solicited via three mechanisms. A Facebook group and a dedicated suggestions mailbox in the application were available for spontaneous feedback, whereas informal focus group discussions were held to solicit more nuanced feedback. Feedback from staff was solicited using an online survey instrument.

Following the success of the pilot, skills and procedure logging on the Vetbox platform was elevated to an integral part of the new core experiential module for the Class of 2016. Refinements were made in response to the findings of the pilot, including mandating feedback from clinicians after an assessment, increased granularity in dashboards detailing student's progress and simplified logging of the skills to one screen.

Another quantum leap facilitated by Vetbox was to embed the new assessment philosophy aimed at achieving greater objectivity. This was done by selecting a subset of the skills and procedures which were to be assessed using an adapted direct observation of procedural skills (DOPS) approach. This involved functionality whereby a student can request an assessment online, and the steps in performing the procedure can be checked off by the assessor against an online checklist in Vetbox and a pass or fail grade can be allocated. The number of procedures in which a student has demonstrated their proficiency using this system contributes to the grade for the core experiential module.

Feedback functionality was added to facilitate subjective assessment such as observation on rotations.

\section{Outcomes assessment}

In keeping with the outcomes-based structure of the 2016 curriculum, the focus of assessment in the latter stages of the program progressively leans towards Day One competencies, culminating in a single exit examination consisting of written and practical components. The logging of exposure and the formative assessments as detailed above are further tools in ensuring the consistent achievement of the desired outcomes.

A structured longitudinal student survey was initiated two years before the launch of the 2016 BVSC programme. This has given a large body of evidence to date on the student experience. One of the major findings which has been translated into curricular change is the lack of sufficient practical work in the programme, which led to the increase of experiential training from two to three semesters. 
While the survey includes graduates, responses from this sector are generally disappointing and there is a clear need to improve this aspect.

Following the recent visitation, the '2016' programme was accredited by the South African Veterinary Council as well as the Royal College of Veterinary Surgeons and the Australasian Veterinary Boards Council.

\section{Discussion}

A number of innovations described in this paper were in response to an accreditation body report. Examples of this are the improved constructive alignment, the core and elective approach to course content, the reduction of content and the documentation of student procedures. This confirms that accreditation, which is a powerful quality control tool internationally, proved also to be a strong driver of change in the project under discussion. It is therefore of concern that veterinary accreditation by statutory bodies is not universal, and that the situation is particularly unsatisfactory in Africa. ${ }^{10}$ Accreditation is also an important benchmarking exercise to the institution under discussion due to its' geographical isolation and unique positioning in the sub region.

This project was beset by the universal truism in veterinary education that teachers resist excluding material, particularly that which falls within their own discipline. This demonstrates the importance of strong leadership, participation of staff based on a solid understanding of the evidence in this regard including that underpinning curricular debulking and the 'just in time' philosophy, ${ }^{11}$ and the strict application of an outcomes orientation in all phases of development. The availability of a purposebuilt mapping tool from the outset may have been another asset in achieving this objective. Mapping content to outcomes allows the identification of material which could be considered to be included in the curriculum 'just in case' and also facilitates the identification of overlapping content which can then be considered for rationalisation. ${ }^{12}$

Initial staff and student involvement was good but waned over the course of the process. We ascribe this to the duration of the project, 'curriculum fatigue' and mission drift. Applying Kotter's change management principles provides further clarification for this and should inform future strategies, considering that curriculum design is an ongoing process. ${ }^{13}$ Specific points, their application to the curriculum design process described here and potential future implications are as follows:

- Establishing a sense of urgency is inherently more difficult in academic circles where established traditions and individual freedom of thought is valued highly. It is clear that a strong sense of urgency was not sustained in this instance;

- Communication of the change vision is even more critical when the process is prolonged and when turnover of people occurs during the project;

- Empowering employees for broad-based action must ideally only be done once there is a clear understanding of the need to change and consensus regarding the vision and strategy. Failure to do so can result in entrenching of established approaches, especially where a culture of protecting one's own discipline at the expense of the greater vision and approach exists;

- Embedding the changed approaches in the culture is crucial to the overall success of the venture. Experience has shown that culture always trumps strategy in influencing behaviour. The realisation that most academics embrace a culture with the belief that it is 'the best' can be leveraged to ensure that 'the best' stands up to evidence and therefore becomes culture.

Besides financial and political, other strong drivers are upon us. The importance of wildlife to the national economy has grown exponentially in recent years. Much of the exposure to wildlife work is dealt with in the elective component, with the extent of focus on wildlife species in the core curriculum open to interpretation. It is envisaged that this will receive attention in future refinements. Calls to respond to cultural imperatives by 'Africanising' the curricula in higher learning are growing, as yet without a clear shared understanding of what this means. The national veterinary services are engaged in a deep-reaching review and restructuring exercise in response to the findings of a report by the OIE. An investigation is also underway into the desirability and feasibility of 
establishing a second veterinary training institution in South Africa. The impact of these are likely to be significant and worthy of reporting as they unfold.

\section{References}

1. Swan GE, Coetzer JAW, Terblache HM. Integrating global animal health, public health and tropical animal health issues into the veterinary curriculum: A South African/African perspective. OIE Rev Scie et Tech 28(2):727-738. 2009

2. Anonymous 2016 FeesMustFall. <https://en.wikipedia.org/wiki/FeesMustFall>. Accessed 15/8/2016. Wikimedia Foundation Inc. 2016

3. Anonymous 2016 RhodesMustFall. <https://en.wikipedia.org/wiki/Rhodes Must Fall>. Accessed 15/8/2016. Wikimedia Foundation Inc. 2016

4. Shay S. Curriculum reform in higher education: A contested space. Teach Higher Ed 20(4):431-441. 2015

5. vandenAkker J, Kuiper W, Hameyer U. Curriculum Landscapes and Trends. Netherlands: Springer Science \& Business Media, 2013.

6. Royal College of Veterinary Surgeons. Criteria and guidance for RCVS approval of veterinary degree courses in the UK and overseas. 2006.

7. University of Pretoria. Strategic Plan: The vision, mission and plan of the University for 2025. <http://www.up.ac.za/media/shared/Legacy/sitefiles/file/publications/2012/eng/strategic plan v11 13feb.pdf>. Accessed 3/3/2016. University of Pretoria. 2016

8. Schank RC. Every curriculum tells a story. Tech Directions 62(2):25-29. 2002

9. Mandler JM, Johnson NS. Remembrance of Things Parsed: Story Structure and Recall. Cog Psych 9:111-151. 1977

10. Bastiaensen P, Rhissa Z, Avong MA, et al. Veterinary statutory bodies in Africa, in OIE Global Conference on Veterinare Education and the Role of the Veterinary Statutory Body 2013.

11. May SA, Silva-Fletcher A. Scaffolded active learning: Nine pedagogical principles for building a modern veterinary curriculum. Jnl Vet Med Ed 42(4):332-339. 2015

12. Harden RM. AMEE Guide No. 21: Curriculum mapping: A tool for transparent and authentic teaching and learning. Med Teach 23(2):123-137. 2001

13. Kotter JP. Leading Change. Boston, Massachusetts: Harvard Business School Press, 1996.

\footnotetext{
${ }^{a}$ Blackboard Learn, Blackboard Inc., Washington DC, USA

${ }^{b}$ www.vetbox.co.za Epi-Use Africa (Pty) Ltd, Pretoria, South Africa
} 